\title{
@City: lecturas tecnológicas de
}

\author{
Barcelona
}

\section{@City: Barcelona's tecnological reedings}

\author{
Jesús Rojas*; Isabel Pellicer**; Valeria Santoro* y Pep Vivas** \\ *Universitat Autònoma de Barcelona \\ **Universitat Oberta de Catalunya \\ pvivasi@uoc.edu
}

\section{Resumen}

El concepto de ciudad contemporánea, del que trata este artículo, rescata la influencia que tiene la tecnología cuando se piensa, se planifica y se vive en una ciudad. Tecnología y ciudad conforman un binomio que replantea las costumbres y las prácticas sociales, incluso puede determinar la manera mediante la cual se puede constituir la propia identidad. Es suficiente observar cómo han ido cambiando las interacciones sociales que se llevan a cabo en las calles, medios de transporte, formas de comprar, trabajar y divertirse, para establecer una relación estrecha entre la tecnología (concretamente TICS) y las formas que van adquiriendo las urbes.

$@$ City es un concepto que pensamos que refleja muy bien las propiedades emergentes de una ciudad actual, esto es, la convivencia de un espacio urbano virtual con uno presencial. Justamente el proyecto 22@Barcelona se ha consolidado como un proyecto que intenta reunir diferentes tipos de espacios. 22@Barcelona, como un barrio de @City, al conjuntar lo presencial con lo virtual crea una frontera incierta y difuminada entre ambos espacios.

Otro factor que nos parece interesante, y que retoma este artículo, se refiere al hecho de poder reflexionar en torno al impacto que tiene esta creación de espacios con procesos psicosociales. Procesos que hablan, por ejemplo, de la vida cotidiana de un barrio, tradicionalmente obrero y ahora fuertemente demarcado por ejes tecnológicos.

Palabras clave: Ciudad, nuevas tecnologías, @City

\begin{abstract}
This article is about the concept of the contemporary city - the influence that technology has when one thinks about, plans and lives in a city. The conjunction of technology and city reformulates customs and social practices; it can even determine the way one constitutes one's own identity. One can see how close the relation is between technology (specifically, TICS) and the structures of the city in a wide variety of situations: in social interactions on the street, in transport, and in ways of buying, of working and entertainment.

"@City" is a concept that very well reflects the emergent properties of a current city, that is, the coexistence of a physical and a virtual urban space. The "22@Barcelona" project attempts to bring together different types of spaces. By combining the physical with the virtual, 22@Barcelona, as a neighborhood of @City, creates an uncertain and blurred border between both spaces.

The article also examines the impact that these spaces have on the psycho-social processes involved in the daily life of a traditionally working-class neighborhood, now strongly limited by technological boundaries.
\end{abstract}

Keywords: City, new Technologies, @City 


\section{Introducción}

Películas como Metrópolis de Fritz Lang en la que la acción transcurre aproximadamente alrededor del año 2026, en una sociedad utópica gobernada por el orden, la limpieza y la tecnología; Blade Runner donde se representa un futuro cuya distancia ficticia de la actual realidad se va reduciendo mientras el 2019 se aproxima; o más recientemente Yo robot, basada en un texto de Issac Assimov, 12 monos, Total Recall... tienen como marco de referencia o como escenario natural la ciudad transfigurada por la tecnología: calles, avenidas y edificios, centros comerciales, medios de transporte o de comunicación, son los elementos que aparecen para darle un sentido distinto a la ciudad. Las relaciones que se establecen por sus arterias, las formas de conducirse por sus calles, los modos distintos de comprar, divertirse o trabajar pasan a ser determinados por un binomio del cual nos queremos ocupar en este escrito: el ciudad y tecnología.

La ciudad que presentamos en este artículo significa la culminación de la influencia de la tecnología sobre la misma y guarda ciertos puntos de conexión con los paisajes urbanos, en los que se desarrollaban las acciones de las películas mencionadas en el párrafo anterior. En la actualidad las fronteras físicas, las formas, los contornos de las ciudades se han resquebrajado. Ello ha provocado la invención de nuevas maneras de concebir, de pensar, de nombrar, de entender... las urbes. En nuestro vocabulario habitual ya no sólo usamos el termino ciudad sino que lo hacemos acompañado de otros prefijos, sufijos y adjetivos: postmetrópolis, metrópolis, ciudad centrípeta, ciudad global, ciudad hojaldre, ciudad difusa, ciudad policéntrica, disurbia, edge-city, heterópolis, hub city, metápolis, post-it city, surfurbia, tecnópolis, etc. La polis actual disgrega también las dimensiones del espacio y del tiempo. La busqueda de estas dimensiones se extiende también por el espacio virtual y provoca que también hablemos de telépolis, ciudad de bits, ciberciudad, ciudad en red, ciudad informacional... y de @City.

Desde nuestro punto de vista, @City recopila en su interior urbano, virtual y presencial, parte de las características de la ciudades del presente. Más que habitar en @City la traspasamos, es decir, vivimos en un flujo constante de imágenes, actividades, interacciones y procesos característicos de la sociedad urbana actual. Las fronteras entre unos aspectos y otros quedan difuminados cotidianamente, por ejemplo, somos capaces de estar a punto de embarcar en un sala de un aeropuerto mirando en la pantalla la hora prevista de salida del avión, leyendo el correo electrónico en nuestro PC, conversando con otra persona a través de nuestro teléfono móvil, etc. Habitamos y practicamos en y de diferentes realidades urbanas día a día, instante a instante... y lo hacemos ya de forma automática. O mejor aún, habitamos y practicamos en la realidad de @City, como se verá más adelante. No sólo vivimos e interaccionamos en esta ciudad sino que la misma sirve para realizar lecturas de nuestras urbes presentes. Con esta intención en este artículo también salimos a pasear por aquella metrópoli que está más próxima, la que vivimos cotidianamente, la que visitamos constantemente: Barcelona.

En el primer apartado, presentamos lo que entendemos por @City mediante la exposición de las conexiones e intersecciones entre la ciudad contemporánea y la tecnología. En un segundo momento presentamos resumidamente el proyecto 22@Barcelona. A partir de aquí, en el tercer apartado, realizamos una lectura desde @City de la transformación que está sufriendo una parte de la ciudad (distrito 22@) para observar finalmente, en el cuarto apartado, que procesos tecnológicos y sociales se están empezando a desarrollar en este barrio de Barcelona y la influencia de éstos en la configuración de la imagen y la identidad colectiva del mismo. 


\section{Conexiones e intersecciones entre la ciudad}

\section{contemporánea y la tecnología: @City}

Las conexiones e intersecciones entre la ciudad contemporánea y la tecnología son múltiples. Algunas de las características de las nuevas tecnologías se incorporan directamente a los nuevos modelos de ciudad: la movilidad, la inmediatez, el cambio constante y, quizás también, la superficialidad y el consumo. Lo tecnológico y la ciudad están en un proceso mutuo de construcción constante, en el cual nosotros también somos construidos y participamos como actores. Las nuevas tecnologías no son sólo procesos que dibujan las nuevas ciudades contemporáneas: nos sirven también como un espejo en el cual mirarnos y mirar la ciudad, intentando abarcar parte de su rapidez. Por lo tanto, las tecnologías son una herramienta que podemos utilizar como investigadores de lo urbano, pero también lentes a través de las cuales podemos observar nuestros espacios cotidianos.

Quizás la metáfora que mejor conecte las ciudades contemporáneas con las nuevas tecnologías sea la que tiende puentes entre lo virtual y lo presencial, elaborando conexiones entre el espacio urbano e Internet. Sólo es necesario recorrer la red para tener la sensación de estar navegando por las calles de una ciudad de ciudades, es suficiente con mirar con detenimiento nuestros movimientos diarios por la ciudad para comprender que la virtualidad atraviesa la gran mayoría de ellos.

Este proceso de convergencia entre las tecnologías y las ciudades no es nuevo, como hemos dicho antes. Sin embargo parece que tiende hacia la aceleración, hacia un posible horizonte en el cual incluso las ciudades dejen de decirse ciudades. Aquello que está claro es que, teniendo en cuenta este proceso, ya no podemos concebir la ciudad sólo como lo hacíamos antes, como una ciudad con un centro y una periferia, desarrollada de dentro hacia fuera, con una historia lineal que se podía aprender paseando por su centro histórico. Metrópolis, postmetrópolis, metápolis, telépolis, edge-city, ciudad global, ciudad informacional, etc. es la tipología urbana de la sociedad actual, surgida de esta nueva forma de concebirla, entenderla y practicarla. A esta tipología queremos añadir en este artículo @City.

@City es la resultante máxima de este proceso de conexión entre las ciudades y las nuevas tecnologías, en ella encontramos algunas características de otras ciudades expuestas por otros autores como tecnópolis, ciudad e-topica, ciudad de los no lugares, etc.

Vamos a detallar como es.

\section{Primera conexión: las tecnópolis}

@City está relacionada directamente con las Tecnópolis anunciadas por Manuel Castells y Peter Hall (1994). Las Tecnópolis aparecen, en la actualidad, como nuevos espacios industriales -tanto por su emplazamiento como por el uso de las nuevas tecnologías de la información y la comunicación- en todos los niveles que son globalmente interdependientes -tanto por los productos resultado de su producción como por el mercado que comparten. Estas Tecnópolis han reestructurado y están reestructurando -física y arquitectónicamente- (Chien-Yuan, 1996) las dimensiones urbanas, regionales y ciudadanas de las diferentes partes de nuestras realidades urbanas, en el contexto de la sociedad de la información y del conocimiento. Es así como algunas ciudades se están convirtiendo en las principales agentes, decisivas para desarrollar la economía global que actualmente sufrimos, compitiendo entre ellas en una carrera de innovación tecnológica e iniciativas empresariales. 
"Este esfuerzo por innovar y por desarrollar de novo adopta muy a menudo la forma de creación y fomento de aquello que hemos denominado 'tecnópolis'. Aquello que ahora necesitamos es una definición más precisa: bajo este nombre se incluyen varios intentos deliberados de planificar y promover, dentro de una área concentrada, una producción relacionada con la industria y tecnológicamente innovadora." (Castells y Hall, 1994: 29).

Los mismos autores proponen, en este sentido, una taxonomía de Tecnópolis. Las primeras, están construidas en un medio innovador y no necesariamente tienen unos límites físicos precisos y claros. Las segundas serian las "ciudades de la ciencia", complejos de investigación exclusivamente científicos, sin que guarden una conexión territorial directa con la producción. Las terceras son los parques tecnológicos (de iniciativas gubernamentales y relacionadas con las universidades) que quieren provocar nuevos tipos de crecimiento industriales, en términos de ocupación y de producción (Pelkonen, 2005). Las cuartas serian aquellas que se desarrollan a través de programas y políticas concretas de Tecnópolis como un instrumento de desarrollo urbano y regional y de relocalización de las actividades industriales y tecnológicas.

Lo cierto es que lo que las cuatro tienen en común, sin ser categorías estáticas y excluyentes entre sí, es la profunda interrelación entre los procesos económicos, la planificación urbana y las nuevas tecnologías (y éstas son unas características típicas aplicables a @City). De este modo se evidencia la importancia que se está dando a la planificación urbana como motor que posibilita el desarrollo tecnológico y económico, desde las administraciones y agentes económicos.

\section{Segunda conexión: la e-topia}

@City también se asemeja a la ciudad de e-topia que se imaginaba William Mitchell (2001) y sirve para orientar algunos de los cambios que forman parte de nuestra realidad urbana contemporánea, contribuyendo a construir un espacio urbano en el que la incorporación de las nuevas tecnologías sirven como propósito de la mejora para el augmento de la calidad de vida. Los efectos de dichas tecnologías suponen, indudablemente, una modificación profunda de las ciudades actuales:

"El sistema digital de telecomunicaciones será para las ciudades del siglo XXI aquello que los canales y la fuerza del trabajo fueron en Amsterdam, Venecia y Suzhou, aquello que las vías, traviesas y trenes a vapor fueron para el Oeste americano, aquello que los túneles del metro fueron para Londres, aquello que el motor de combustión interna y la autopista de hormigón fueron para las zonas suburbanas del sur de California y aquello que la electrificación y el aire acondicionado fueron para Phoenix" (Mitchell, 2001: 19-20).

En estos momentos estamos experimentando un aumento de interconexiones entre nosotros, las personas, a través de las denominadas nuevas tecnologías de la información y la comunicación (Haythornthwaite, 2001), como nunca antes en la historia de la humanidad. Y a la vez, con la implementación de sistemas digitales a diferentes niveles del ámbito urbano, entre nosotros y todos aquellos elementos urbanos y sociales que nos rodean; tenemos constantemente la necesidad de interaccionar con toda una serie de aparatos cuando queremos realizar cualquier actividad cotidiana (sea del tipo que sea). Hasta en la composición del aire de nuestras ciudades encontramos nuevos elementos (redes sms, wireless, bluetooth, etc.) que facilitan relaciones sociales y que nos ayudan a desarrollar nuestras actividades laborales, de ocio y de tiempo libre. 
En e-topía, por tanto, las redes no solamente se extienden por el aire. También están insertadas en los edificios mismos que habitamos. En nuestras ciudades actuales, la arquitectura está evolucionando de tal manera que se conecta, se relaciona, se imbrica directamente con nosotros, es decir, permite considerar los espacios arquitectónicos como "robots dónde habitar" (Mitchell, 2001), edificios que están a nuestra disposición, que facilitan nuestro bienestar personal y social, que modifican nuestros estilos de vida:

"En el pasado lejano, un edificio era poco más que un esqueleto y piel. A partir de la revolución industrial, adquirieron una elaborada fisiología mecánica -sistemas de calefacción, ventilación y aire acondicionado, suministro de agua y eliminación de residuos, sistemas de energía eléctrica y otros tipos, sistemas de circulación mecánica, hidráulica, una amplía variedad de instalaciones de seguridad y de protección-; [...]. Actualmente, a comienzos de la revolución digital, los edificios están siendo dotados de sistemas nerviosos artificiales, sensores, pantallas y equipos controlados por ordenador; la estructura se un chasis para sofisticados sistemas electrónicos que juegan un papel cada vez más importante en la respuesta a las necesidades de sus habitantes" (Mitchell, 2001: 65).

Cada vez más se construyen edificios, islas de casas, manzanas, barrios, etc., en los que los sistemas (eléctrico, calefactor, visuales...) están conectados a un ordenador central que graba y gestiona la información y el conocimiento de dichos espacios. El software instalado en estos espacios se convierte en algo tan esencial como el tejado y las paredes de las mismas.

\section{Tercera conexión: los "no lugares"}

@City también está repleta de "no lugares". La definición de "no lugar" es comprensible en tanto que los lugares, los espacios, los sitios y los territorios, son interpretados como piezas importantes en la construcción social de las identidades individuales y colectivas de las personas. Dicho de otra manera, los espacios actúan no sólo como el trasfondo en el que ponemos en marcha nuestras relaciones sociales, sino también como el sitio en el que quedan y se van acumulando las historias particulares de cada uno y a la vez de la historia social de una población. Teniendo en cuenta estos aspectos se resalta la importancia que los lugares tienen como espacios de significación, en los cuales sólo podíamos realizar una serie concreta de actividades, generalmente muy bien definidas.

Los "no lugares" vienen a modificar dicha estabilidad, potencian la realización de muchas actividades simultáneas (mezcla de producción, de ocio o de consumo), multitud de ocupaciones que se pueden hacer al mismo tiempo que nos movemos, paseamos o viajamos, gracias a la posibilidad que nos ofrecen las nuevas tecnologías de la información y de la comunicación. Así pues, en los "no lugares", las operaciones sociales se multiplican copiosamente y de ello se deriva que estos espacios se hayan convertido en instalaciones imprescindibles para nuestras circulaciones e interacciones cotidianas.

La casuística de los "no lugares" puede ser muy extensa: las autopistas (y también sus áreas de descanso), los habitáculos móviles (los medios de transporte como los aviones, los trenes, los automóviles, etc.) y sus estructuras físicas y arquitectónicas (los andenes, los intercambiadores, las estaciones ferroviarias, los aeropuertos), las estaciones aeroespaciales, las grandes cadenas hoteleras, los parques de recreo, los hipermercados (o centros comerciales) y también podríamos añadir: las plazas duras, los puertos, los establecimientos alquilados por alguna franquicia empresarial, etc. 
Podemos observar en la ciudad de los "no lugares", del mismo modo que Marc Auge (1995) lo hacía, los procesos habituales que se realizan en los "no espacios", (desde la compra de un brick de caldo en la máquina dispensadora de alimentos, pasando por la compra de una entrada en un cajero automático, hasta ver una película en unos multicines y finalmente la utilización de la tarjeta de crédito para pagar los gastos generados por la estancia en un hotel (de cualquier compañía hotelera). Con la utilización de la tecnología, y siempre siguiendo a Auge (1995), aquello que hacemos es establecer una especie de contrato con los "no-lugares"; contrato relacionado directamente con la identidad individual de quien lo subscribe y que se hace visible de forma constante y de maneras diferentes. Un ejemplo de forma expresa es a través del billete que se presenta al revisor o a la azafata, del tren o del avión, cuando entregamos y pagamos el ticket a la salida de la autopista de peaje y de forma tácita, y también vinculante, cuando por ejemplo, empujamos los carros de la compra que los hipermercados ponen a nuestra disposición.

Sin pararnos ni un instante en nuestros lugares nos dedicamos en @City a traspasar por los "nolugares" (sin que nadie nos moleste y acompañados por la tecnología). De hecho, las prácticas urbanas cotidianas están siendo conformadas por dicha movilidad y conforman, cada vez más, una transformación de lugares en "no lugares". En definitiva, nuestros devenires personales y sociales pasan por nuestra vivencia de los nuevos espacios urbanos, y traspasan (y nunca mejor dicho) estos "no-espacios", construyendo identidades e interacciones específicamente urbanas.

\section{Cuarta conexión: las telépolis}

@City también se relaciona directamente con la realidad virtual. En el contexto virtual, todo aquello que ocurre no es sólo "una simulación de aquello que es real en la naturaleza y en las ciudades, sino que amplía y extiende la noción de realidad. Se aprovecha la capacidad de los seres humanos para generar nuevas modalidades de realidad" (Echevarría, 2000: 120). Este es otro motivo por el que la ciudad contemporánea y la red estén tan próximos: ambos se inscriben en la corriente de la artificialización que caracteriza la cultura actualmente dominante. Dicho de otro modo: desde un cierto punto de vista, se podría asumir que el espacio virtual es mejor cuanto mejor simula aquello que representa; cuanto más "realismo" imprime a sus imágenes y sonidos urbanos.

Pero el entorno virtual también genera nuevos mundos, nuevos sujetos, nuevos objetos y desde nuestro punto de vista nuevas ciudades, a través de unas características estructurales específicas (siguiendo de nuevo a Echevarría, 2000). No se trata únicamente de una ampliación de funciones de la ciudad real, de una especie de prolongación de ella. Algo existe en estos espacios que los hace distintos, que les da un funcionamiento e identidad diferente. Puede decirse que se trata de espacios informacionales (que funcionan mediante representaciones electrónicas de los sujetos y objetos), comprimidos, multisensoriales, digitales... Pero si hay dos características que afectan particularmente a la metáfora virtual en relación con el espacio urbano, estas son que el espacio virtual es distal (los agentes pueden interactuar en gran distancia) y reticular (su tipología está basada en redes, no en recintos). En este sentido, no es difícil de entender que relacionamos el espacio urbano con Internet. De hecho, Raúl Trejo (1999) apunta que:

"Internet es un medio específica e intensamente urbano. Las redes de información, en su extensión, desorden y disparidad, se asemejan a las autopistas y avenidas de cualquiera de las megalópolis contemporáneas. Como en ellas, en Internet hay 
zonas de luces y otras, de sombras. Existen rutas directas y atajos bruscos; espacios de reflexión y muchos más, de diversión". (Trejo, 1999)

Este carácter urbano ha permitido que se considere la red como un espacio paralelo, superpuesto y, en ocasiones, incluso que substituye al de la ciudad. Además de pasear por las calles, hoy nos dedicamos a pasear por la red: buscando trabajo, comprando, conociendo a otras personas o, simplemente, entrando en espacios que nunca antes habíamos visitado. De este modo Internet se ha convertido en una gran ágora de uso común, en un lugar de encuentro por excelencia y sobretodo en la manifestación más clara (aunque nos cueste contemplarlo a través de la red) de la diversidad de personas y culturas, que nos encontramos en las metrópolis on-line y off-line al inicio de este milenio.

\section{Quinta conexión: la ciberciudad}

En @City también encontramos algunas características típicas del "ciberespacio". Algunos discursos interpretan a éste último (su medio "físico") como una metrópolis compuesta por datos tridimensionales codificados en formas arquitectónicas por las que se puede navegar y los cibernautas (sus habitantes) como un nuevo tipo de ser humano, basado en la superación de las barreras entre ordenador y usuario. Lo cierto es que la "ciberciudad" es considerada generalmente aún como una ficción. Es pertinente, por tanto, que nos preguntemos de donde surge nuestro interés por ella.

Por una lado, el enfoque que aquí nos interesa es aquel que nos permite aplicar al ciberespacio las calidades del entorno urbano "real" y viceversa, expresando la interconexión cada vez más acusada entre los dos (Benedikt, 1991; Lemley, 2002).

Por otro lado, podemos considerar @City, desde este enfoque, como una ciudad/metáfora en la cual las dimensiones de tiempo y espacio de la ciudad tradicional están siendo modificadas y reconstruidas por el impacto de las nuevas tecnologías, particularmente por Internet, para convertirse en un:

"fluido de imágenes sin relación espacial y temporal entre ellas, ya que se emiten todas a la vez. [En la ciberciudad] los límites desaparecen y los espacios urbanos se sumergen en un continuo, mientras el tiempo se reduce a repeticiones compulsivas" (García, 2004: 183).

Pero sobre todo, @City, nos interesa porque genera preguntas sobre la relación entre espacio virtual y presencial. El espacio virtual está cada vez más presente y parece innegable que se entrelaza constantemente con el presencial en los espacios urbanos actuales. Pero como plantea Carlos García (2004: 189): "¿es aceptable describir la pantalla del ordenador como un espacio habitable y no como una abstracción de la realidad? ¿Es aceptable separar tan radicalmente lo real (el cuerpo) de lo virtual (la mente)? ¿No será la ciberciudad un relato de ciencia-ficción tras el cual se oculta la incapacidad de fundar una investigación seria y profunda sobre los verdaderos efectos que las nuevas tecnologías están ejerciendo sobre las ciudades?".

\section{Una nueva realidad urbana: @City}

Habitamos pues en la sociedad urbana de @City, en la que pasamos constantemente de una red a otra, de una realidad (presencial) a otra (virtual), sin que apenas nos demos cuenta de ellos. Para 
caminar por @City, para poder realizar los "pasos" correspondientes, usamos diferentes medios tecnológicos: "el automóvil o el tranvía permiten cambiar de barrio para ir al trabajo o ir en busca del ocio. Así mismo la misma pantalla del ordenador permite pasar en pocos segundos del universo de trabajo al de la familia. El teléfono móvil permite pasar de una conversación directa con los amigos a una conversación con otros interlocutores. Los medios de transporte y comunicación permiten cambiar el campo social, pasar del medio profesional al club deportivo, de una relación de vecinos de barrio a una emoción compartida con persones que viven cerca de alguien, pero que comparten las mismas pasiones. Las persones se desplazan pues, tanto de manera virtual como real, en universos sociales diferentes que articulan en cada caso según una configuración diferente. Metafóricamente, se podría ver como una especie de hipertexto donde las palabras funcionan como vínculos entre un conjunto de textos informáticos. El hipertexto es un procedimiento que permite acceder, por medio de un 'clic' sobre la palabra de un texto, a esta misma palabra a una serie de textos. En un hipertexto, cada palabra pertenece simultáneamente a diferentes textos; en cada uno de ellos, participa en la producción de sentidos diversos en interacción con otras palabras del texto, en ocasiones según sintaxis diferentes en cada texto. La digitalización de las imágenes ha abierto la posibilidad de construir hipermedias, los cuales establecen relaciones con otros textos, documentos sonoros e imágenes (el prefijo hiper se usa aquí en el sentido matemático de hiperespacio, es decir, espacio de n dimensiones)" (Ascher, 2004: 357). La piel de @City está recubierta por esta estructura de hipertexto que nos permite, pasar de un medio a otro, participar en múltiples interacciones, participar de un sinfín de significados urbanos, etc.

Gracias a este conjunto de conexiones e intersecciones sabemos, ahora si, que la ciudad contemporánea está imbricada (más que en cualquier otro momento) con la tecnología. La tecnología invade y mediatiza los aspectos arquitectónicos, económicos, comunicativos y políticos de las ciudades. También es necesario destacar cómo en @City la tecnología está incidiendo y transformando nuestra forma de interaccionar con y en la ciudad, nuestras formas de practicar la ciudad, de movernos por ella, de viajar, etc. @City actúa aquí como concepto paraguas que engloba algunas de las características que conceptos anteriores no habían considerado de forma elocuente, como tecnópolis, ciudad e-topica, ciudad de los no lugares, etc. El concepto de @City también toma en cuenta cómo a partir del discurso urbano actual se construye en estos momentos la identidad colectiva de la ciudad.

\section{La "nueva" Barcelona}

22@ es un proyecto urbanístico que se inició en el año 2000 en el noroeste de Barcelona y permitirá, a lo largo de los años previstos de su actuación, de 15/20 años, construir $3.200 .000 \mathrm{~m}^{2}$ de nuevo techo y techo rehabilitado para usos productivos; edificar entre 3.500 y 4.000 nuevas viviendas sometidas a régimen de protección, obtener $220.000 \mathrm{~m}^{2}$ de suelo aproximadamente para nuevos equipamientos y zonas verdes y aumentar entre 100.000 y 130.000 los puestos de trabajo localizados en la zona. Por lo tanto dicho proyecto está transformando 200 hectáreas de suelo industrial de Poblenou, con las características típicas del Eixample Cerdà, en una zona innovadora con excelentes infraestructuras (concentrando estratégicamente las actividades relacionadas con la información y el conocimiento). En esta superficie deben convivir diferentes ambientes: empresas tecnológicamente avanzadas, universidades, centros de formación continua y centros de investigación y de transferencia de tecnología, con las actividades de proximidad del barrio -comercio, pequeños talleres, servicios- configurando un rico tejido productivo. 
El 22@ dota con esta fórmula mixta, un uso nuevo al tejido industrial del antiguo barrio del Poblenou. Crea un nuevo modelo urbano que substituye el tradicional y exclusivo uso industrial, por una utilización del espacio con actividades igualmente productivas pero que se encuentran en sintonía con los requerimientos relacionados con un modelo urbano de alta calidad, mixto, ecológicamente eficiente y con un fuerte peso económico, que se imbrica con la actividad productiva del barrio. "Se propone para ello la reurbanización completa a través de un Plan Especial que mejore los servicios urbanos introduciendo energías renovables; una red de climatización centralizada por manzanas; telecomunicaciones con banda ancha; aprovechamiento de las aguas freáticas; una red de recogida pneumática de residuos; galerías de servicios [...] Otro de los aspectos singulares del proyecto es que no determina un destino, ni edificabilidad fijos, aun a pesar de que fija las grandes magnitudes [...]. Se establece una calificación genérica que de hecho admite una pautada diversidad de usos: residencial, industrial @, oficinas, viviendas, dotaciones y equipamientos @ (formación y investigación...) (Sabaté, 2005: 65). En otras palabras, 22@ es un proyecto que quiere responder a la necesidad de recuperar el dinamismo económico y social de una de las antiguas áreas industriales de la ciudad de Barcelona, creando con ello un entorno diverso y compacto, donde los espacios productivos puedan convivir con centros de investigación, formación continua y transferencia tecnológica, viviendas protegidas, equipamientos y zonas verdes que ayuden a mejorar la calidad de vida y de trabajo.

Con dicho proyecto, se potencia que la ciudad se ubique claramente en una sociedad y economía actual y global etiquetada y basada en el conocimiento y la información. La transformación arquitectónica, social y económica del barrio contempla no sólo el desarrollo de la tecnología más avanzada, sino también la potenciación de practicas relacionadas con la cultura, la educación, el audiovisual, etc., es decir, actividades imbricadas directamente con la información y las comunicaciones.

En resumen, el 22@ ha pasado a convertirse de un distrito industrial a uno tecnológico; un sitio, con un decorado tecnológico, donde confluyen todo tipo de servicios para vivir y trabajar en él.

\begin{tabular}{|l|}
\hline Datos del proyecto \\
\hline Ámbito: $198,26 \mathrm{Ha} ; 1.159 .626 \mathrm{~m} 2$ de suelo 22@ \\
\hline Potencial total de techo: $4.000 .000 \mathrm{~m} 2$. \\
- Actividades productivas: $3.200 .000 \mathrm{~m} 2$. \\
- Otros usos (equipamientos, viviendas...): $800.000 \mathrm{~m} 2$. \\
\hline Vivienda: \\
- Se reconocen 4.614 viviendas preexistentes \\
\hline Incremento de zonas verdes: 114.000 m2 de suelo. \\
\hline Nuevos equipamientos: $145.000 \mathrm{~m} 2$ de suelo. \\
\hline Incremento de puestos de trabajo: 130.000. \\
\hline
\end{tabular}




\section{Lecturas de Barcelona desde @City}

@City es la conjunción entre la ciudad presencial y la ciudad virtual, el lugar en el cual las barreras entre estas dos ciudades se difuminan; el espacio dónde el proceso de transformación tecnológica se hace más presente y dónde la tecnología habitualmente forma parte de nuestra cotidianidad urbana. En este apartado pretendemos ilustrar, desde la visión más tecnológica de la ciudad a características propias del proyecto 22@. A la vez, estaremos realizando una lectura de cómo se está construyendo la Barcelona actual y del futuro.

El 22@ contiene características de las Tecnópolis planteadas anteriormente, en el sentido de que para llevar a cabo dicho proyecto se están desarrollando en el barrio unos programas y unas políticas muy concretas para desarrollar urbanística, local y regionalmente acciones que recuperan las antiguas actividades industriales del Poblenou, pero sobretodo se está potenciando la aparición de actividades relacionadas con las nuevas tecnologías.

Con el sentido apuntado actualmente a la renovación del Poblenou se potencia la interrelación entre los procesos económicos, la planificación urbana y las nuevas tecnologías, gracias a la participación de las administraciones y las agentes económicos. Esta es otra de las características que tipologizan al 22@ en el contexto de las Tecnópolis.

El proceso de reconversión a Tecnópolis, y por tanto a @City, queda contextualizado de la siguiente manera. Atraídos por la cercanía de la ciudad y la disponibilidad de agua, los empresarios textiles de finales del siglo XIX, en Cataluña, empezaron a instalar sus fábricas en el barrio de Poblenou, sitio en que de forma paulatina fueron sumándose fábricas pertenecientes a otros sectores: artes gráficas, alimentación, etc. Este barrio sobrevivió como centro industrial hasta mediados del siglo XX, cuando se inició el traslado de las fábricas a la periferia y su espacio quedó ocupado por grandes almacenes y agencias de transporte. Tras varias décadas de decadencia, el barrio sufre su primera gran transformación y posterior renovación a finales de los años 80, con la construcción de la Vila Olímpica con motivo de los Juegos de Barcelona'92.

La transformación que ha sufrido el citado barrio engloba lugares como Can Jaumeandreu. Hace falta acercarse a la calle de Rambla del Poble Nou (núm. 152) para poderse hacer una idea de cómo era la ciudad de Barcelona, en términos industriales, a finales del siglo XIX. Asimismo, en contraste con la remodelación de Can Jaumeandreu, vale la pena cruzar la Diagonal y acercarse a Ca l'Aranyó (Llacuna/Tànger), fábrica textil en proceso de rehabilitación. Integrada en el Plan 22@, Ca l'Aranyó, formará parte del Parc Barcelona Mèdia, un gran complejo dedicado al sector audiovisual. A pocos metros, la antigua fábrica textil de Josep Canela (Ciutat de Granada, 131) acoge el Institut Català de la Tecnologia, centrado en la formación de nuevos profesionales. Al descender por la misma calle Ciutat de Granada se encuentra otro ejemplo de aprovechamiento de antiguas estructuras: la reconversión de naves industriales en lofts. La mejor muestra es El Vapor Llull (Llull, 133), una empresa de productos químicos reconvertida en naves de residencia y trabajo, ocupadas normalmente por talleres de artistas, siguiendo el modelo del Soho de Nueva York. Otra muestra de lofts se encuentra en la calle Pallars, entre Ciutat de Granada y Roc Boronat, aunque en esta ocasión 
en construcciones de nueva planta. En la misma calle Pallars, en el tramo cercano a la rambla del Poble Nou, destaca un conjunto de muros repletos de grafitos. Los grandes espacios de las naves industriales también han sido aprovechados como discotecas, convirtiendo al Poblenou en una de las zonas de ocio nocturno de la ciudad. Y finalmente debemos destacar el complejo de Can Ricart como una de las piezas de mayor interés del patrimonio industrial del barrio.

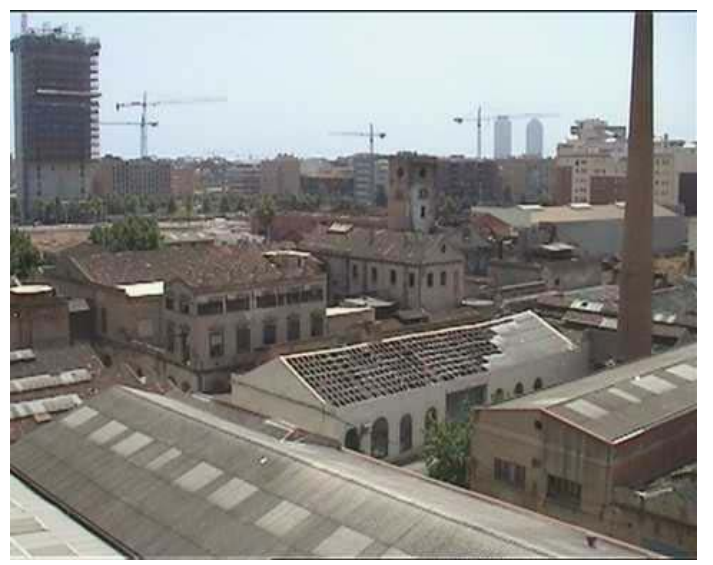

Imagen 1: el complejo de Can Ricart en l'actualidad. Fuente: http://www.quoniam.info/bloc/2006/11/la-ra-de-la-ignorncia.html

Toda esta transformación y conservación del patrimonio industrial del Poblenou se regulariza a través del plan Especial de Protección de Patrimonio Industrial del Poblenou que tiene como objetivo potenciar el proceso de recuperación de algunos de los símbolos de la historia industrial del barrio. A parte de los ejemplos mencionados, se prevé la conservación de un total de 114 elementos (46 ya estaban catalogados y 68 se incluyen de nuevo) y contribuirá a garantizar la preservación de ese legado de interés histórico y cultural.

Siguiendo con nuestra lectura del 22@, este también se asemeja a la ciudad e-tópica. La red del subsuelo del barrio da cobertura a diferentes sistemas de telecomunicación (telefonía básica, sistemas de conexión de alta velocidad como XDSI, ADSL... y servicios de cable, acceso a fibra óptica, etc.).

Con estos sistemas se moderniza las redes de telecomunicaciones y permite la libre competencia de proveedores de servicios y contenidos de telecomunicaciones. A su vez, están dotadas de canalizaciones completamente registrables que permiten a los operarios realizar mejoras e implicaciones de los servicios sin tener que intervenir en la vía pública.

La red no sólo se extiende por el suelo y el subsuelo, sino también lo hace por medio del sistema wi-fi gracias al proyecto Wi-Fi Barcelona. Este proyecto tiene como prioridad desplegar en los espacios públicos del distrito 22@Barcelona cobertura de acceso wi-fi con la intención de disponer de acceso a la red desde cualquier lugar, plaza, calle, etc., del barrio.

Pero en el 22@, teniendo en cuenta las características de la ciudad e-tópica, la cuestión tecnológica también se aplica: 
a) al sistema de recogida de residuos. El sistema seleccionado, pneumático, permite seleccionar en origen el residuo con la intención de minimizar el uso de los contenedores de basuras, por tanto se promueve el reciclaje de subproductos. El Plan Especial de Infraestructuras de Poblenou propone dotar a la zona de una red de recogida que sirva para los actuales edificios y para los que se construyan de nuevo. Las terminales de recogida que se construyen en los edificios de nueva planta y en la calle en zonas ya edificadas permiten realizar una recogida selectiva de cuatro fracciones. Los edificios tienen dos buzones de recogida en cada planta (orgánica y rechazo) y dos buzones situados en el vestíbulo de cada edificio (para el papel y los envases). El cartón y el cristal se recogen mediante contendores convencionales.

b) al uso eficiente de la energía (de la energía eléctrica y del condicionamiento de los edificios). En todo el ámbito del 22@ se aplica una metodología etiquetada como demand side management que se concreta en un conjunto de medidas de gestión integral con el objetivo de aumentar la eficiencia del consumo final de energía y redistribuir las curvas de consumo de una manera más regular. Para poderlo llevar a cabo se plantea la microgeneración de energía en el contexto del barrio. Además de la generación local, el sistema energético se fundamenta en unas redes de suministro desarrolladas en el 22@, dotadas con la máxima potencia del servicio, interconectadas y flexibles. El acoplo y la compatibilidad entre las redes eléctricas, de gas y la climatización es fundamental para conseguir un sistema de alta viabilidad y buen rendimiento energético.

En relación a las energías renovables, la energía solar se aprovechará para generar energía térmica y energía eléctrica mediante los sistemas fotovoltaicos conectados a la red general eléctrica. La energía del subsuelo se aprovechará mediante bombas de calor.

Se está implementando en los edificios sistemas centralizados de climatización para el frío y el calor. La producción se realiza mediante la cogeneración y la red de distribución de tubos de agua fría y caliente. Los sistemas centralizados de climatización (district or local heating and cooling systems, district energy system) proveen a los diferentes edificios de la energía térmica necesaria para su climatización. Los edificios se conectan mediante una red de distribución a las plantas de producción. La finalidad principal de este sistema es la de ofrecer un servicio de climatización a los ocupantes de los edificios de la zona 22@ (empresas, escuelas, administración pública, otros equipamientos...). Con este servicio se aumenta la calidad del entorno urbano, se mejora la eficiencia energética y disminuye el impacto ambiental relacionado con el uso de la energía.

Así pues, la zona del 22@, a través de su modelo de recogida selectiva de residuos y a través de su modelo energético, dibuja un mapa que conecta los edificios y el subsuelo a través de la red de tuberías, de redes de suministro energético, de válvulas, de tubos, de plantas de producción, de buzones de entrega de residuos y de centrales de recogida por las cuales transitan los diferentes residuos y los diferentes tipos de energía que generan (que necesitan tanto los particulares como las empresas del barrio).

22@ se caracteriza también por la concentración de no lugares a lo largo de su territorio. El mapa de estos no lugares es el siguiente. Hay en la zona dos centros comerciales. En el núcleo de las Glòries hallamos el primer centro comercial que se construyó en Barcelona. Posteriormente, durante la celebración del Fòrum 2004, también se edificó el centro comercial de Diagonal Mar. En esta zona también se hallan ubicados otros espacios descritos anteriormente en la ciudad de los no lugares, como las cadenas de hoteles y el nuevo Centro de Convenciones de Barcelona, incorporados al paisaje urbano de esta zona con unas dimensiones físicas y con unas características arquitectónicas 
similares a las de un aeropuerto. En esta zona también encontramos otros no lugares, por ejemplo las plazas duras (Plaza Ernest Lluch, Plaza del Fòrum, etc.), la estación de metro de Maresme-Fòrum, la estación del tranvía de Fòrum. Sin duda, las estaciones de metro y las estaciones del tranvía (e incluso el mismo tranvía) son instalaciones que están muy presentes en la trama urbana del 22@. La línea 1, 2, 4 del metro provoca que a lo largo de su recorrido vayan apareciendo en el terreno diferentes estaciones de metro (Llacuna, Poblenou, Selva de Mar) y las líneas del tranvía T4 y T5 traviesan y bordean el 22@. Otra infraestructura que podemos catalogar dentro de los no lugares de esta zona es l'avenida Diagonal. Esta vía en forma de autopista conecta la plaza de Llevant con la plaza de les Glòries y se convierte en la arteria principal de todo el barrio. No es la única "autopista" que aparece en su trama. Delimitando toda la zona se ubican la Gran Via y la Ronda del Litoral. Estos son algunos ejemplos de no lugares que encontramos en el 22@ aunque en un futuro están proyectados otras grandes infraestructuras que provocarán la aparición de nuevos no lugares, el intercambiador de las Glòries, la construcción de la futura línea 8 del metro, la finalización de la línea T5 del tranvía y la prolongación de la línea 4 del metro hasta la estación del AVE de la Sagrera.

El 22@ aparece así como un referente de las tendencias más actuales en materia de infraestructuras, arquitectura y urbanismo. Entre otras cuestiones, eso quiere decir que el barrio se verá transformado a nivel de accesibilidad y de movilidad, que se ajustaran a unos aspectos medioambientales claramente definidos como queda ampliamente especificado en el Plan de Movilidad. "El plan de Movilidad tiene el objetivo que a partir del 2010, más del $70 \%$ de las personas que se desplacen al distrito 22@Barcelona lo haga en transporte público, a pie o en bicicleta. Por ello establece importantes mejoras en la red de transporte público y crea una extensa red de carriles para bicicletas (29 km.) y favorece la fluidez de la circulación. A su vez garantiza la disponibilidad de plazas de aparcamiento para trabajadores y visitantes en todo el sector, establece medidas para favorecer la fluidez del tráfico rodado e introduce nuevos mecanismos para la reducción de la contaminación acústica y medioambiental." (Ayuntamiento de Barcelona en www.22barcelona.com).

Una vez terminada la transformación del 22@ éste deberá afrontar los flujos de movilidad sin que ello signifique provocar colapsos, donde existirá un tránsito regulado por sus calles y donde se minimizará su impacto medioambiental.

En este barrio a parte de las estructuras tradicionales propias de la ciudad encontramos otras de más novedosas (descritas con anterioridad) que los proyectistas han intentado poner en orden. El metro, servicios de suministros diversos, recogida de basuras, cables, hilos y fibras ópticas, nodos, etc. han sido ubicados por el subsuelo construyendo un entramado subterráneo. Tranvía, autobuses, transportes privados y peatones, se mueven por superficie ordenados por la señalización y la semaforización. Todos estos elementos y otros tendrán que buscar una armonía que, hoy en día, la misma ciudad de Barcelona tiene como asignatura pendiente

La conexión entre la ciudad simulada del 22@y la ciudad física del 22@ es muy clara. El mapa del subsuelo del 22@ es muy similar al mapa físico. El vínculo entre los dos mapas es evidente en estas dos imágenes (la primera virtual y la segunda presencial). La estructura urbanística ideada por Cerdà, característica de la ciudad, se reproduce en la el mapa de estructuras virtual y también se extiende a ambos lados de la Diagonal. Las conexiones en red se establecen en los dos niveles: en la trama urbana y en la malla de infraestructuras. La forma en red se repite en ambos. 
El 22@ no solamente se relaciona con la realidad virtual en este sentido. Como proyecto de renovación urbana y, por tanto, como plan urbanístico, transforma arquitectónicamente la ciudad y se transmuta con la clara intención de crear una nueva imagen del barrio, más "tecnológica". Situando Barcelona en el contexto de las ciudades que apuestan por las tecnologías de la información y del conocimiento.

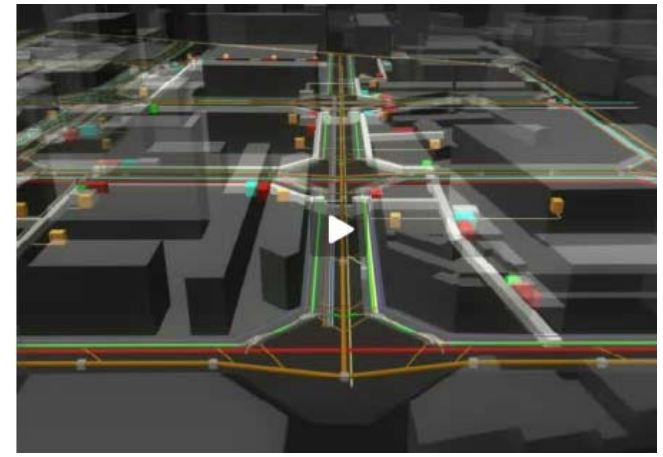

Imagen 2: fragmento mapa estructuras del 22@.

Fuente: http://www.22barcelona.com/

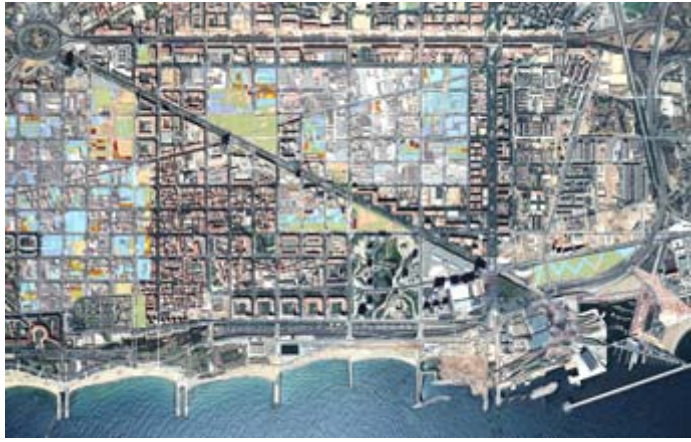

Imagen 3: mapa físico del 22@. Fuente: http://www.22barcelona.com/

Significa crear un "nuevo" centro para una ciudad, incorporando un elemento que complementa la ciudad turística y de negocios que ya es Barcelona. No es casual que una de las imágenes que Barcelona vende en la actualidad sea la Torre Agbar, diseñada por Jean Nouvel. Sin duda, este edificio, una de las puertas de entrada del 22@, es un símbolo fruto del diseño de su construcción, de su forma de iluminarse y de la tecnología aplicada. Una Barcelona plenamente integrada al contexto social tecnológico que estamos viviendo. El triangulo de las puertas de entrada de esta "nuevo punto central estratégico" de Barcelona se complementa con el edificio del Forum y con la estación del AVE de la Sagrera (en proyecto de construcción). El nuevo barrio del 22@ y la ciudad están incorporando e incorporaran en su imaginario colectivo estas tres imágenes más actuales, mezcla de tecnología, de negocio y de la arquitectura más actual.

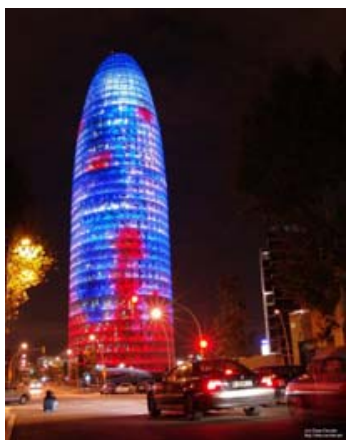

Imagen 4: Torre Agbar.

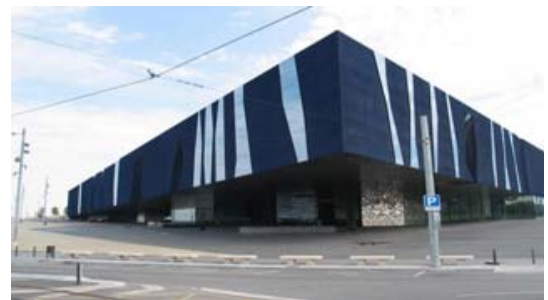

Imagen 5: Edificio del Fórum.

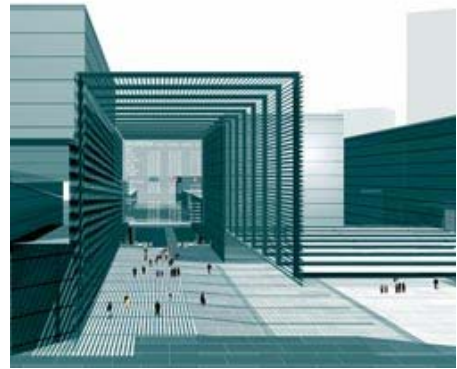

Imagen 6: Estación del AVE de la Sagrera.

Imágenes que parecen que procedan de una realidad simulada por ordenador. Imágenes de un futuro presente. Al igual que estos edificios, el barrio del 22@ ha necesitado de la simulación para poderse proyectar y diseñar. El 22@ simulado está transformando y está reconstruyendo al antiguo barrio del Poblenou de tal manera que la realidad urbana virtual se impone a la antigua realidad urbana 
industrial (aunque se quieren conservar algunos elementos de esta trama a través de la conservación de algunos edificios y fábricas emblemáticas).

\section{(22) Barcelona}

Al principio de este artículo nos habíamos planteado que la influencia de la tecnología en la ciudad es algo perceptible, de tal suerte, que sus formas físicas y contornos (de la urbe) se han resquebrajado. Las diferentes visiones que hoy podemos relacionar con el escenario de la ciudad (postmetrópolis, metrópolis, ciudad centrípeta, tecnópolis, ciberciudad...) pasan necesariamente por el tamiz tecnológico.

@City es justamente un modelo social, económico y político de cómo tendremos que empezar a pensar las ciudades en adelante y 22@Barcelona es un buen ejemplo de ello.

@City representa un entorno virtual y presencial urbano. Cuando pensamos/vivimos esta ciudad, habitamos en un flujo constante de imágenes, actividades, interacciones, procesos y prácticas sociales que son características de un entorno urbano tecnológicamente operativo: nuevas y más patentes conexiones, TIC's; nuevos espacios industriales y educativos que provocan una profunda modificación en la forma en que se perciben y, sobretodo, se planifican las urbes. 22@ es un barrio que puede marcar la pauta de aquello en que poco a poco se transformaran las ciudades.

Los edificios, calles, centros, instalaciones, suministros, zonas verdes y en general la idea holística del espacio adquiere esta nueva marca @, la cual significa que la relación de la tecnología con la ciudad hace de esta última un nuevo lugar donde habitar. Significa también que la marca @ entra a formar parte de los procesos sociales que construyen la realidad urbana actual.

Por ejemplo, la identidad colectiva de un antiguo barrio obrero (como por ejemplo el Poblenou) ha sido desplazada, poco a poco, por la intresubjetividad @: una identidad tecnológicamente construida. Las actividades con las que nos podremos encontrar en @City son todas aquellas que utilizan el talento tecnológico como principal recurso productivo, con independencia del sector económico al que pertenezcan. Éstas están relacionadas con la investigación, el diseño, la edición, la cultura, la gestión de bases de datos o la actividad multimedia, se caracterizan por hacer un uso intensivo de las tecnologías de la información y la comunicación y de la ocupación del espacio. Estas prácticas son las que se están fomentando en la actualidad y se han ido instalando en el 22@ de Barcelona, dándole una apariencia distinta al barrio. Por ejemplo, la fusión e instalación de instituciones que guardan relación directa con el uso o la producción de nuevas tecnologías, en y con los edificios industriales y tradicionales, provoca que las prácticas sociales se transformen mediatizadas por esta tecnología.

Otras habilidades que se están desarrollando, a través de diferentes proyectos, con el propósito de fomentar el uso de las nuevas tecnologías de la información y de la comunicación, en la vida cotidiana y facilitar la comunicación entre las personas, a través de diferentes objetivos son:

- Acercar las ventajas que ofrecen Internet y las tecnologías de la información y la comunicación a diversos colectivos, mejorando con ellos su calidad de vida laboral y cotidiana. 
- Conseguir que el vecindario del distrito sea pionero en la incorporación de las nuevas tecnologías, en la vida cotidiana.

- Colaborar con todas aquellas entidades, empresas e instituciones del barrio comprometidas con el progreso social.

- Aprovechar las modernas infraestructuras del distrito 22@Barcelona para crear nuevos servicios basados en las nuevas tecnologías.

Por otro lado, @City incorpora también nuevas formas de interpretar el espacio. Definiciones de no lugar pueden adquirir sentido en esta nueva forma de planificar las ciudades, pues si consideramos que los espacios de significación son tradicionalmente aquellos donde se llevan a cabo determinado tipo de actividades, el concepto de no lugar viene a modificar dicha estabilidad ya que la marca @ incorpora espacios simultáneos con relaciones fugaces, movilidad permanente, etc. Las nuevas prácticas urbanas que se suceden en la realidad @ se sostienen mayoritariamente por la movilidad y, en definitiva, las prácticas y las interacciones sociales, la manera como se construyen las identidades, etc., éstas adquieren nuevas formas tecnológicamente posibles. El 22@Barcelona permite reflexionar en torno a estos nuevos procesos.

\section{Referencias}

Ayuntamiento de Barcelona (2007). 22@Barcelona. El distrito de la innovación. Available from http:// www.22barcelona.com Last accessed: 30-4-2007

Ascher, François. (2004). Multi-mobility, multispeed cities: a challenge for architects, town planners and politicians. En Antoni Font (ed.). The explosion of the City, Morphologies, Observations and Motions (pp. 352-363). Barcelona: Col·legi d'Arquitectes de Catalunya: Barcelona.

Augé, Marc. (1992). Los no-lugares. Espacios del anonimato. Barcelona: Gedisa.

Benedikt, Michael. (1991). Cyberspace: Some Proposals. En Michael Benedikt (ed.). Cyberspace: First Steps. Cambridge M.A: The MIT Press.

Castells, Manuel y Hall, Peter. (1994). Technopoles of the World: The Making of 21. st. Century. Industrial Complexes. New York: Routledge.

Chien-Yuan, Lin. (1996). Technopolis Development: An Assessment of Hsinchu Experience. Research Review of Regional Development, 8, 371-390.

Echeverría, Javier. (2000). Un Mundo Virtual. Madrid: Plaza \& James.

García, Carlos. (2004). La ciudad hojaldre. Visiones urbanas del siglo XXI. Barcelona: Gustavo Gili.

Haythornthwaite, Carolina. (2001). Introduction. The Internet in Every Day Life. American Behavioral Scientists, 45(3), 363-382.

Lemley, Mark. (2002). Place and Cyberspace. California Law Review, 91, 521-542.

Mitchell, William. (2001). E-topia: Urban Life, Jim--But Not As We Know It. Cambridge M. A: MITT Press. 
Pelkonen, Antti. (2005). State Restructuring, Urban Competitiveness Policies and Technopole Building in Finland: A Critical View on the Glocal State Thesis. European Planning Studies, 13(5), 685-706.

Sabaté, Joaquín (2005). Luces y sombras en el proyecto urbanístico reciente de Barcelona. En Marisa Carmona (ed). Globalizacion y Grandes Proyectos Urbanos (pp. 57-68). Buenos Aires: Ediciones Infinito.

Trejo, Raúl. (1999). Internet y sociedad urbana. Cuando el ciberespacio y la calle se complementan. Available from http://raultrejo.tripod.com/ensayosInternet/Internetyciudad.htm Last accessed: 21-5-2005

\section{Historia editorial}

Recibido: 20/11/2006

Aceptado: $14 / 02 / 2007$

\section{Formato de citación}

Rojas, Jesús; Pellicer, Isabel; Santoro, Valeria; Vivas, Pep (2007). @City: lecturas tecnológicas de Barcelona. Athenea Digital, 11, 114-131. Disponible en http://psicologiasocial.uab.es/athenea/index.php/atheneaDigital/article/view/384/329.

Jesús Rojas. Doctor en Psicología social por la Universitat Autònoma de Barcelona y licenciado en Psicología por la Universidad nacional Autónoma de México.

Isabel Pellicer. Licenciada en Psicología en la Universitat Oberta de Catalunya.

Valeria Santoro. Licenciada en Psicología en la Universitat Autònoma de Barcelona.

Pep Vivas. Doctor en Psicología social por la Universitat Autònoma de Barcelona. Máster en Intervención ambiental: contextos psicológicos, sociales y de gestión. 


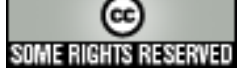

Este texto está protegido por una licencia $\underline{\text { Creative Commons. }}$

Usted es libre de copiar, distribuir y comunicar públicamente la obra bajo las siguientes condiciones:

Reconocimiento: Debe reconocer y citar al autor original.

No comercial. No puede utilizar esta obra para fines comerciales.

Sin obras derivadas. No se puede alterar, transformar, o generar una obra derivada a partir de esta obra.

\section{$\underline{\text { Resumen de licencia }}$}

$\underline{\text { Texto completo de la licencia }}$ 